\title{
Elevated Levels of Somatic Mutation in a Manifesting BRCA1 Mutation Carrier
}

\author{
Stephen G. GRANT, ${ }^{1,2,3 *}$ Rubina DAS, ${ }^{1}$ Christina M. CERCEO, ${ }^{1}$ Wendy S. RUBINSTEIN, ${ }^{4,5}$ Jean J. LATIMER ${ }^{2,3}$ \\ ${ }^{1}$ Department of Environmental and Occupational Health, Graduate School of Public Health, ${ }^{2}$ Department \\ of Obstetrics, Gynecology and Reproductive Sciences, School of Medicine, University of Pittsburgh, ${ }^{3}$ Center for \\ Environmental Oncology, University of Pittsburgh Cancer Institute, Pittsburgh, PA, ${ }^{4}$ Department of Medicine, \\ Northwestern University Feinberg School of Medicine, Chicago, IL, ${ }^{5}$ Evanston Northwestern Healthcare Center \\ for Medical Genetics, Evanston, IL, USA
}

Homozygous loss of activity at the breast cancerpredisposing genes $B R C A 1$ and $B R C A 2$ (FANCD1) confers increased susceptibility to DNA double strand breaks, but this genotype occurs only in the tumor itself, following loss of heterozygosity at one of these loci. Thus, if these genes play a role in tumor etiology as opposed to tumor progression, they must manifest a heterozygous phenotype at the cellular level. To investigate the potential consequences of somatic heterozygosity for a BRCA1 mutation demonstrably associated with breast carcinogenesis on background somatic mutational burden, we applied the two standard assays of in vivo human somatic mutation to blood samples from a manifesting carrier of the Q1200X mutation in BRCA1 whose tumor was uniquely ascertained through an MRI screening study. The patient had an allele-loss mutation frequency of $19.4 \times 10^{-6}$ at the autosomal GPA locus in erythrocytes and $17.1 \times 10^{-6}$ at the X-linked HPRT locus in lymphocytes. Both of these mutation frequencies are significantly higher than expected from age-matched disease-free controls $(P<0.05)$. Mutation at the HPRT locus was similarly elevated in lymphoblastoid cell lines established from three other BRCA1 mutation carriers with breast cancer. Our patient's GPA mutation frequency is below the level established for diagnosis of homozygous Fanconi anemia patients, but consistent with data from obligate heterozygotes. The increased HPRT mutation frequency is more reminiscent of data from patients with xeroderma pigmentosum, a disease characterized by UV sensitivity and deficiency in the nucleotide excision pathway of DNA repair. Therefore, this BRCA1associated breast cancer patient manifests a unique phenotype of increased background mutagenesis that likely contributed to the development of her disease independent of loss of heterozygosity at the susceptibility locus. (Pathology Oncology Research Vol 13, No 4, 276-283)

Key words: somatic mutation, hypoxanthine-guanine phosphoribosyl transferase, glycophorin A, BRCAl gene, inherited breast cancer syndrome, Fanconi anemia, xeroderma pigmentosum

Received: Febr 23, 2007; accepted: Sept 21, 2007

Correspondence: Stephen G. GRANT, Center for Environmental Oncology, University of Pittsburgh Cancer Institute, 5150 Centre Avenue, Pittsburgh, PA, 15232, USA. Tel: (412) 623-1180, fax: (412)623-3201,E-mail: grantsg@upmc.edu

*This work was supported by the following grants and institutions: NIH grant CA 71894, US Army BRCP grants BC991187, BC996714 and BC9963444, Susan G. Komen Foundation grant BCTR0403339, the Ruth Estrin Goldberg Foundation and the Pennsylvania Department of Health.

Abbreviations/acronyms: AT, ataxia telangiectasia; FA, Fanconi anemia; GPA, glycophorin A; HNPCC, hereditary non-polyposis colorectal cancer; HPRT, hypoxanthine-guanine phosphoribosyltransferase; $\mathrm{M}_{f}$, mutation frequency; MRI, magnetic resonance imaging; NER, nucleotide excision repair; XP, xeroderma pigmentosum

\section{Introduction}

One of the greatest advances in our understanding of cancer etiology has been the identification of subsets of patients exhibiting hereditary susceptibility to the disease. Cancer susceptibility occurs in two distinct forms. The first involves very rare, usually recessive disorders with very high cancer incidence that often have a spectrum of developmental symptoms detectable at birth or in early childhood. Examples include such syndromes as ataxia telangiectasia (AT), Fanconi anemia (FA) and xeroderma pigmentosum (XP), diseases that have been known for decades. Cloning and characterization of the underlying 
genetic defects in these diseases has shown that they are associated with deficiencies in the various processes of DNA repair. The second type of cancer susceptibility is more subtle, usually associated with cancer incidence in early adulthood, with few or no other phenotypic manifestations. These diseases are considered to be genetically dominant and, as they occur in patients with no other symptoms, their tumors are often considered to be sporadic in the absence of a considerable family history or molecular analysis. Examples of these disorders include Li-Fraumeni syndrome and Lynch syndrome II or hereditary nonpolyposis colorectal cancer (HNPCC). The underlying defect in these diseases has been identified as heterozygosity for inactivation of recessive oncogenes known as tumor suppressors. Thus, although the tumor-promoting phenotype is recessive at the cellular level, the high incidence of somatic segregation of heterozygous alleles causes it to be effectively dominant at the organismal level. For many years it has been speculated that there might be some connection between these two types of cancer susceptibility.

The breast cancer susceptibility syndromes associated with mutational inactivation of the BRCA1 and $B R C A 2$ genes are considered to be of the second type of cancerprone diseases, almost by definition establishing these genes as tumor suppressors. They have also been implicated in DNA repair processes, however, suggesting that they may, in fact, be "mutator" genes like those responsible for the recessive cancer syndromes. ${ }^{1}$ This situation became clearer when it was recently discovered that homozygosity for mutations in the BRCA2 gene was responsible for FA patients of complementation group D, identifying it also as the FANCD1 gene. ${ }^{2}$ The tumor suppressor genes that are the genetic basis of HNPCC are known to be involved in post-replicative repair of base mismatches in $\mathrm{DNA}^{3}$ and the p53 gene, the basis of $\mathrm{Li}^{-}$ Fraumeni syndrome, is involved in repressing gene amplification, ${ }^{4}$ so both of these syndromes could be considered as "mutator" gene syndromes as well.

The possibility that BRCAl heterozygotes manifest a cellular phenotype promoting carcinogenesis has been investigated with conflicting results; most studies showing no hypermutability in these cells or individuals, ${ }^{5},{ }^{6}$ while others have reported high spontaneous frequencies of mutation $^{7}$ and/or hyperinducibility. ${ }^{8}$

There are two widely applied methods of measuring somatic mutation in humans, both blood cell-based. ${ }^{9}$ The clonogenic HPRT assay involves chemical selection for inactivation of the X-linked housekeeping gene hypoxanthine-guanine phosphoribosyltransferase in cultured lymphocytes. The flow cytometric glycophorin A (GPA) assay is based on detection and quantitation of somatic "allele loss" mutations at the glycophorin A locus on chromosome 4. The GPA assay is potentially sensitive to a broad spec- trum of mutational mechanismus, including point mutation, small insertions and/or deletions, chromosomal aneuploidy, epigenetic gene inactivation, homologous or nonhomologous recombination. ${ }^{10}$ The HPRT assay is sensitive to point mutations, small insertions and deletions, but large deletions and chromosome loss are inviable, and recombination appears to be suppressed, probably due to X-inactivation.

Previous studies have shown an association between human in vivo somatic mutation level and elevated risk of cancer, ${ }^{11-14}$ particularly in the so-called "DNA repair deficiency" diseases AT, FA and Bloom syndrome, which show 10-, 50- and 100-fold increases in GPA mutation frequencies, respectively. ${ }^{15}$ Epidemiological evidence also suggests that the otherwise asymptomatic heterozygotes for the radiation-sensitivity syndrome AT are predisposed to breast cancer. ${ }^{16,17}$ We recently reported the detection of a mammographically undetectable breast tumor in an MRI pilot screening program of young, high-risk women. ${ }^{18}$ In the present study, mutation frequencies $\left(\mathrm{M}_{f}\right)$ at the GPA and HPRT reporter loci are measured in this breast cancer patient, who is now known to be a carrier for an inactivating mutation of the BRCAl gene.

\section{Materials and Methods}

The patient was a 36-year-old woman with strong family history of breast cancer (two affected first degree relatives) recruited into a clinical trial of MRI screening for young woman at high risk for breast cancer with dense breast tissue. ${ }^{18}$ She was subsequently found to carry a Q1200X premature termination mutation in the BRCAl locus. ${ }^{19}$ Despite recent negative mammography, gadolinium enhancement images revealed a small, $1 \mathrm{~cm}$ lesion in the upper-outer quadrant of the left breast, identified pathologically as an infiltrating ductal carcinoma. The patient underwent a modified radical mastectomy of the left breast and chose to also undergo a contralateral prophylactic total mastectomy. Blood was obtained for analysis with consent under Magee-Womens Hospital/University of Pittsburgh IRB \# MWH-94-108.

\section{HPRT and GPA somatic mutation analyses}

The HPRT and GPA somatic mutation assays were performed on blood samples obtained from the patient and concurrent disease-free controls. The clonogenic HPRT assay was performed by the method of O'Neill et al. ${ }^{20} \mathrm{~T}$ lymphocytes were stimulated to proliferate in culture and enzyme-deficient mutant clones selected in the presence of the toxic nucleoside analog 6-thioguanine. Results for the concurrently analyzed normal control, an $\mathrm{M}_{f}$ of $5.0 \times 10^{-6}$, were consistent with our previous experience with this individual $(P=0.45, z$ test $)$, who has been analyzed 6 other 


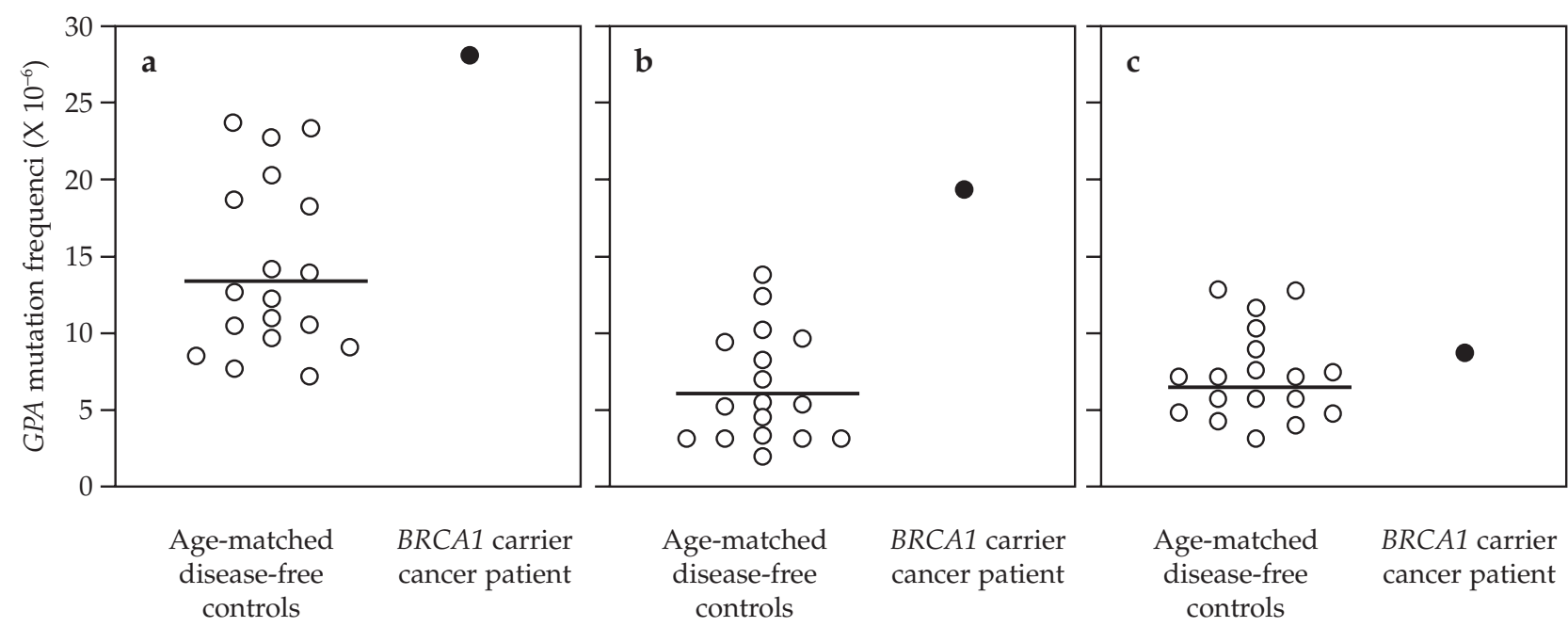

Figure 1. GPA $M_{f}$ of the hereditary breast cancer patient and 18 age-matched controls (35-39 years). (a) Total GPA: bar indicates average $M_{f}$ of control population, $14.0 \pm 5.6 \times 10^{-6}$. The patient's result is significantly higher than the $M_{f}$ of this limited control population ( $P=0.005$ ). (b) Allele loss: bar indicates average $M_{f}$ of control population, $6.6 \pm 3.4 \times 10^{-6}$. The patient's $M_{f}$ is significantly higher than that of the controls $(P=0.0001)$. (c) Loss and duplication: bar indicates average $M_{f}$ of the control population, $7.4 \pm 2.8 \times 10^{-6}$. The patient's result is not significantly different from the $M_{f}$ of these controls $(P=0.30)$.

times in our laboratory, yielding an average $\mathrm{M}_{f}$ of $8.6 \pm 3.3$ x $10^{-6}$ (mean \pm standard deviation).

Briefly, the GPA assay involves labeling of the two polymorphic forms of the erythrocyte cell-surface protein glycophorin A with monoclonal antibodies followed by flow cytometric analysis to quantify cells with variant phenotypes associated with bone marrow somatic mutation. ${ }^{21}$ The patient had the most informative genotype for this analysis, heterozygosity for the MN blood group. Results for the concurrently analyzed normal control (total GPA $\mathrm{M}_{f}, 12.6 \times 10^{-6}$, allele loss $6.0 \times 10^{-6}$, loss and duplication $\left.6.6 \times 10^{-6}\right)$ were consistent with our previous experience with this individual $(P=0.17,0.28$ and 0.17 for total $G P A$ $\mathrm{M}_{f}$, allele loss frequency and loss and duplication frequency, respectively, $z$ tests), who has been analyzed 11 other times in our laboratory, yielding a total GPA $\mathrm{M}_{f}$ of $9.5 \pm$ $1.3 \times 10^{-6}$, an allele loss frequency of $5.1 \pm 0.8 \times 10^{-6}$ and a loss and duplication frequency of $4.4 \pm 0.8 \times 10^{-6}$.

\section{Controls}

Normal GPA $\mathrm{M}_{f}$ for comparison were derived from our control database, which is under continuous revision and supplementation, and contains historical as well as contemporaneous data. Several subsets of these data have been published. ${ }^{22-24}$ Normal HPRT $\mathrm{M}_{f}$ for comparison are derived from a number of published reports ${ }^{25-31}$ as well as our own contemporaneous data. GPA $\mathrm{M}_{f}$ from homozygous and heterozygous FA patients were taken from the report of Sala-Trepat et al. ${ }^{32}$ and our own ongoing analy$\operatorname{ses}^{33,34}$ of clinical samples and samples provided from the International Fanconi Anemia Registry (IFAR). HPRT $\mathrm{M}_{f}$ from homozygous and heterozygous FA patients were derived from Vijayalaxmi et al. ${ }^{35}$ and Sala-Trepat et al. ${ }^{32}$ GPA allele loss $\mathrm{M}_{f}$ from XP homozygotes were reported in Langlois et al. ${ }^{15}$ HPRT $\mathrm{M}_{f}$ in XP homozygotes and heterozygotes were compiled from a number of reports. ${ }^{12,36-42}$

\section{Lymphoblastoid cell lines}

Three lymphoblastoid cell lines from breast cancer patients confirmed as heterozygous for inactivating mutations in the BRCAl gene were obtained from the Coriell Cell Repositories (Camden, NJ): GM13708, GM13709 and GM13712, as well as 9 control cell lines: AG09393, AG09980, AG10111, GM00946, GM01814, GM03797, GM05380, GM14448 and GM14820.

\section{Statistical analysis}

Analysis of individual results in the context of control populations was done with the $z$ test at $\propto=0.05$ on lntransformed data. Comparisons between populations were performed with the $t$ test assuming unequal variances on similarly transformed data or the nonparametric Mann Whitney $U$ test at the same level of significance.

\section{Results}

Somatic mutation at the autosomal GPA locus

The patient's total GPA $\mathrm{M}_{f}$ was found to be $28.2 \times 10^{-6}$. $\mathrm{M}_{f}$ at this locus are known to be significantly age-dependent, ${ }^{22,43}$ so the patient's result is compared with normal women \pm 2 years from her age in Fig. 1 , and against the 
Table 1. GPA mutation frequencies for normal and DNA repair-deficient patients and populations

\begin{tabular}{|c|c|c|c|c|c|}
\hline \multirow[b]{2}{*}{ Population } & \multicolumn{3}{|c|}{$G P A M_{f}\left(x 10^{-6}\right)$} & \multicolumn{2}{|c|}{ Patient } \\
\hline & $N$ & Mean $\pm S D$ & Range & Percentile & $P^{1}$ \\
\hline \multicolumn{6}{|l|}{ a) all mutant classes } \\
\hline Patient & & 28.2 & & & \\
\hline Normal controls & 644 & $16.6 \pm 16.3^{2}$ & $0.19-79.3$ & 0.91 & 0.22 \\
\hline FA patients & 63 & $455.8 \pm 751.6^{3}$ & $49.4-4257.4$ & 0.02 & 0.022 \\
\hline FA carriers & 36 & $31.9 \pm 36.7^{4}$ & $6.2-90.2$ & 0.66 & 0.42 \\
\hline \multicolumn{6}{|c|}{ b) allele loss mutants only } \\
\hline Patient & & 19.4 & & & \\
\hline Normal controls & 644 & $6.7 \pm 4.3^{5}$ & $0.01-34.5$ & 0.97 & 0.001 \\
\hline FA patients & 63 & $379.9 \pm 737.9^{6}$ & $24.6-4084.0$ & 0.02 & 0.047 \\
\hline FA carriers & 36 & $10.4 \pm 8.0^{7}$ & $1.0-37.4$ & 0.90 & 0.11 \\
\hline $\mathrm{XP}$ patients & 7 & $4.6 \pm 4.3$ & $1.0-2.2$ & 1.00 & 0.028 \\
\hline \multicolumn{6}{|c|}{ c) allele loss and duplication mutants only } \\
\hline Patient & & 8.8 & & & \\
\hline Normal controls & 644 & $9.2 \pm 11.8^{8}$ & $0.01-152.3$ & 0.67 & 0.47 \\
\hline FA patients & 63 & $74.0 \pm 56.3^{9}$ & $6.2-270.4$ & 0.03 & 0.016 \\
\hline FA carriers & 36 & $20.5 \pm 31.7^{10}$ & $4.0-152.8$ & 0.43 & 0.31 \\
\hline
\end{tabular}

${ }^{1} z$-test for patient data ${ }^{2}$ excluding outlier with total GPA $\mathrm{M}_{f}$ of $6.7 \times 10^{-3} 3$ excluding outliers with total GPA $\mathrm{M}_{f}$ of 7.4, 8.0 and $9.9 \times 10^{-34}$ excluding outlier with total GPA $\mathrm{M}_{f}$ of $2.7 \times 10^{-4} 5$ excluding 6 outliers with GPA allele loss $\mathrm{M}_{f}$ of $4.5,4.8,7.1,7.7,7.8$, and $16.2 \times 10^{-5}$ excluding 3 outliers with GPA allele loss $\mathrm{M}_{f}$ of 7.0, 7.9 and $9.8 \times 10^{-37}$ excluding outlier with GPA allele loss $\mathrm{M}_{f}$ of $4.4 \times 10^{-58}$ excluding outlier with GPA loss and duplication $\mathrm{M}_{f}$ of $8.7 \times 10^{-4}$ excluding 2 outliers with GPA loss and duplication $\mathrm{M}_{f}$ of 3.2 and $3.5 \times 10^{-4}{ }^{10}$ excluding outlier with GPA loss and duplication $\mathrm{M}_{f}$ of $2.6 \times 10^{-4}$

$\mathbf{M}_{f}$ of our entire normals database, age-adjusted, in Table 1. Although she appears to have a somewhat elevated total GPA $\mathrm{M}_{f}$ (Fig. 1), in the $91^{\text {st }}$ centile for the entire control database, it is not significantly higher than that expected for her age (Table 1). The GPA assay also allows for the straightforward characterization of mutations into two broad classes; those arising by simple allele loss and those arising by allele loss accompanied by duplication of the remaining allele..$^{9,10,21}$ The patient's allele loss $\mathrm{M}_{f}$ was $19.4 \times 10^{-6}$, and her loss and duplication $\mathrm{M}_{f}$ was $8.8 \times 10^{-6}$ (note that the two add up to her total $G P A \mathrm{M}_{f}$ ). It can now be seen that the elevation in the patient's $\mathrm{M}_{f}$ is confined to the allele loss class of variation, where it is unambiguously significant (Fig. 1 and Table 2).

\section{Somatic mutation at the X-linked HPRT locus}

The patient's HPRT $\mathrm{M}_{f}$ was found to be $17.1 \times 10^{-6}$. Once again, in vivo $\mathrm{M}_{f}$ at the HPRT locus are known to be age-dependent, ${ }^{25,44,45}$ so the patient's result is compared to normal women \pm 2 years from her age in Fig. 2, and against the $\mathbf{M}_{f}$ of our entire normals database, age-adjusted, in Table 2. Compared to the subset of age-matched controls, the patient's $\mathrm{M}_{f}$ does not appear to be unusually high (Fig. 2), but in comparison with the entire database it does just reach significance (Table 2). To confirm this result, we obtained lymphoblastoid cell lines from 9 disease-free controls and 3 additional breast cancer patients with known inactivating mutations in the $B R C A l$ gene (all nonsense mutations resulting in premature truncation of the protein product). The HPRT $\mathbf{M}_{f}$ for the normal cell lines was $8.8 \pm 6.8 \times 10^{-6}$, not significantly different from our in vivo controls $(P=0.69)$. The mean HPRT $\mathrm{M}_{f}$ for the 3 heterozygous BRCAl patient cell lines (Fig. 2) was 16.7 $\pm 1.2 \times 10^{-6}$, not significantly different from the in vivo result from our patient $(P=0.63)$, but signification higher than that of the in vitro controls $(P=0.009)$. This effect is accentuated by combining the in vivo and in vitro data $(P$ $<0.0001)$.

\section{Discussion}

In vivo somatic $\mathrm{M}_{f}$ in a breast cancer patient heterozygous for an inactivating mutation in the BRCAl gene was significantly elevated over disease-free controls; 1.7 -fold in the case of GPA $\mathrm{M}_{f}$ and 2.3-fold in the case of in vivo HPRT $\mathrm{M}_{f}$. The latter result was confirmed in a study of lymphoblastoid cell lines derived from breast cancer patients, which exhibited a 1.9-fold increase in HPRT $\mathrm{M}_{f}$ over similar controls. These increases are similar to those observed in analyses of $\mathrm{M}_{f}$ in blood samples from sporadic 
cancer patients: 1.7-fold increases in both $H P R T^{12}$ and GPA $\mathrm{M}_{f}{ }^{14}$ In breast cancer patients these increases in $\mathrm{M}_{f}$ are 1.3-fold for $H P R T^{46}$ and 1.5 -fold for $G P A{ }^{47}$ In our hereditary breast cancer patient, this increase becomes 2.9-fold if only the "allele loss" class of GPA mutation is considered, a pattern that is consistent with induced mutation by most genotoxic exposures, including ionizing radiation, ${ }^{9}$ and the elevated spontaneous $\mathbf{M}_{f}$ observed in patients with AT. $^{24}$ This pattern suggests that haploinsufficiency for BRCAl does not affect the incidence of mitotic recombination (including gene conversion) or chromosome missegregation, as they result in allele loss and duplication. Possible mechanisms associated with the observed increase in simple allele loss still range from

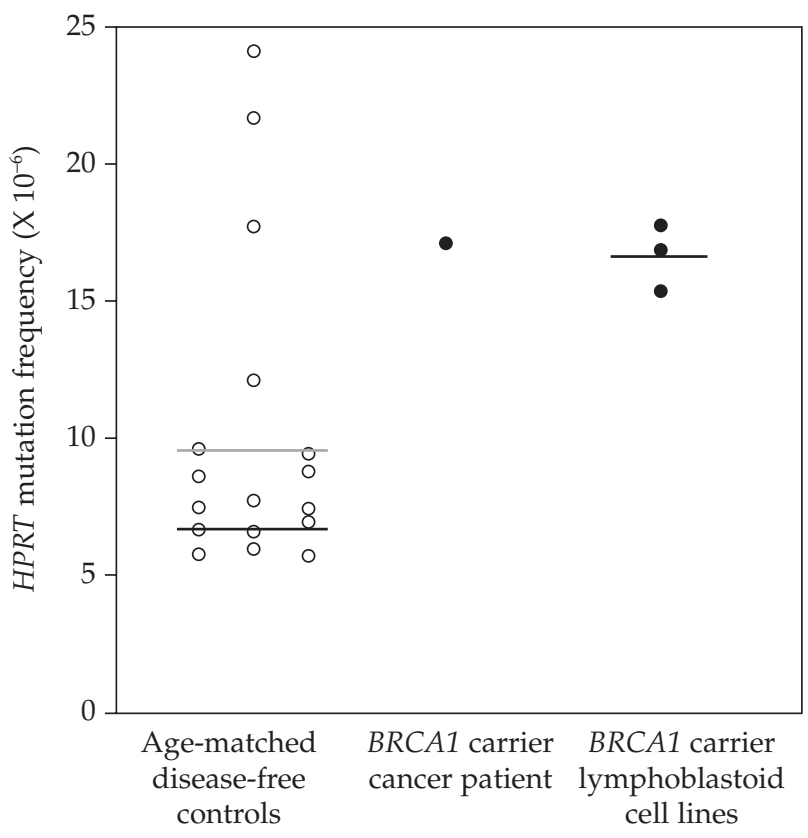

Figure 2. HPRT $M_{f}$ of the hereditary breast cancer patient, 18 age-matched controls (35-39 years), 3 lymphoblastoid cell lines derived from hereditary breast cancer patients and 9 lymphoblastoid cell lines derived from disease-free controls. The solid bars represent the average $M_{f}$ for the control population $(9.7 \pm 5.8 x$ $\left.10^{-6}\right)$, heterozygous $B R C A 1^{+/}$cell lines $\left(16.7 \pm 1.2 \times 10^{-6}\right)$, and control cell lines $\left(8.8 \pm 6.8 \times 10^{-6}\right)$, respectively. The patient's result itself is not significantly higher than that of this restricted set of controls $(P=0.092)$, but the average $M_{f}$ of the 3 patientderived lymphoblastoid cell lines is, both alone $(P=0.048)$ and with the addition of the patient's lymphocyte-derived data $(P=$ 0.022). The lighter line represents the average $M_{f}$ of the entire control database age-adjusted to that of the patient (Table 2). point mutations and small, intragenic insertions and deletions to large-scale, cytogenetically detectable chromosome deletion and even whole chromosome loss, ${ }^{10,21}$ however, since we observed a comparable increase in mutation frequency at the X-linked HPRT locus, and major deletions and chromosome loss are inviable at this locus ${ }^{48}$ it would appear that BRCAl heterozygosity is associated with gene-specific rather than regional mutational susceptibility.

In patients with FA, we have found a consistent increase in allele loss $\mathrm{M}_{f}$, but a variable increase in the frequency of loss and duplication. ${ }^{33,34}$ Since the BRCAl gene has been functionally linked to the FA repair system, ${ }^{1}$ deficiency for this gene might be expected to produce a similar phenotype. As can be seen from Table 1, however, the GPA $\mathrm{M}_{f}$ of our BRCAl heterozygote was significantly lower than those seen in FA patients, both in total and in each mutational subclass. A more valid comparison, however, is to compare the patient's results to those of FA heterozygotes, who do seem to have a subtle mutational susceptibility phenotype. ${ }^{32-34}$ While the overall increase in GPA $\mathrm{M}_{f}$ in our patient is certainly consistent with that observed in FA heterozygotes, the pattern does not match, with the patient's increase occurring in the allele loss class and the FA heterozygotes primarily increased in loss and duplication $\mathbf{M}_{f}$.

Somewhat surprisingly, FA patients do not exhibit an increased $\mathrm{M}_{f}$ at the HPRT locus, ${ }^{32}$ although they have a significant shift in their HPRT mutational spectrum towards gene deletions. ${ }^{49,50}$ These two apparently contradictory findings are rationalized by invoking the wellestablished limited viability of these cells, especially in the presence of genotoxic agents. ${ }^{51,52}$ Indeed, in the present analysis FA patients actually exhibit a significantly lower HPRT $\mathrm{M}_{f}$ than controls $(P=0.037)$ (Table 2$)$. FA heterozygotes, however, exhibit an increased HPRT $\mathbf{M}_{f}$, which, although not significant in either of the original reports, ${ }^{32,35}$ is highly significant in our pooled analysis $(P<$ 
0.001). This increase in HPRT $\mathrm{M}_{f}$ is consistent with those observed in our BRCAl carriers, both in vivo (Table 2 ) and in vitro $(P=0.10)$.

Another possible explanation for the increased mutation frequency we have observed in BRCAl heterozygotes is an effect on the nucleotide excision DNA repair pathway (NER). This pathway repairs DNA damage that causes a distortion in the DNA helix, notably intrastrand linkages caused by UV irradiation and bulky adducts such as those caused by exposure to polycyclic aromatic hydrocarbons, and deficiency in this DNA repair system is associated with the cancer-predisposing disease XP. ${ }^{53}$ Overexpression of BRCAl has been shown to enhance NER capacity, ${ }^{54}$ probably through transcriptional regulation of NER genes. ${ }^{55}$ Several studies have suggested that breast cancer patients have lower NER capacity than the normal population, ${ }^{56-58}$ and we have shown that early stage breast tumors are consistently deficient in this type of DNA repair. ${ }^{47}$

The phenotype of XP patients seems to be the opposite of that of FA patients: they exhibit significantly increased HPRT $\mathrm{M}_{f},{ }^{12,36-42}$ but there is no evidence of an effect on $G P A \mathrm{M}_{f}^{15}$ (Tables 1 and 2). In our pooled analysis, the increase in $H P R T \mathrm{M}_{f}$ is highly significant $(P=0.008)$, and is consistent with that of our BRCAl carrier patient (Table 2) and data from the heterozygous BRCAl lymphoblastoid cell lines $(P=0.23)$. XP heterozygotes also exhibit a slightly increased HPRT $\mathrm{M}_{f},{ }^{37-39}$ although it does not reach statistical significance $(P=0.16)$. Since XP patients have been identified with as much as $50 \%$ residual NER activity, ${ }^{53}$ it is reasonable that heterozygotes should express a detectable phenotype, but, since the HPRT $\mathrm{M}_{f}$ increase in XP homozygotes is only on the order of 2-fold it would require analysis of a much larger population of heterozygotes to achieve statistical significance. Again, however, the results from our patient (Table 2), and the BRCAl carrier cell lines $(P=0.22)$ are not significantly different from those of the population of XP carriers.

BRCAl carriers therefore manifest a unique phenotype with respect to mutational susceptibility that may be related to their tumor incidence. A more significant deficiency in BRCAl activity arises during tumorigenesis when the locus undergoes loss of heterozygosity, but this is likely to play a greater role in tumor progression.

\section{Acknowledgements}

We would like to thank our clinical collaborators on this project, Drs. Jules H. Sumkin, Amal Kanbour-Shakir and Victor G. Vogel for their cooperation with this study, Dr. Richard D. Day for statistical advice, and to acknowledge the work of our clinical coordinator, Michelle B. Huerbin. We greatly appreciate the technical contributions of Manda Welsh, Beatriz Zayas-Rivera, Bob Babra and Jennifer Adair to this study.

\section{References}

1. D'Andrea $A D$, Grompe $M$ : The Fanconi anaemia/BRCA pathway. Nat Rev Cancer 3: 23-34, 2003

2. Howlett NG, Taniguchi T, Olson S, Cox B, Waisfisz Q, De DieSmulders C, Persky N, Grompe M, Joenje H, Pals G, Ikeda H, Fox EA, D'Andrea AD: Biallelic inactivation of BRCA2 in Fanconi anemia. Science 297: 606-609, 2002

3. Papadopoulos N, Lindblom A: Molecular basis of HNPCC: mutations of MMR genes. Hum Mutat 10: 89-99, 1997

4. Livingstone LR, White A, Sprouse J, Livanos E, Jacks T, Tlsty $T D$ : Altered cell cycle arrest and gene amplification potential accompany loss of wild-type p53. Cell 70: 923-935, 1992

5. Nieuwenhuis B, Van Assen-Bolt AJ, Van Waarde-Verhagen MA, Sijmons RH, Van der Hout AH, Bauch T, Streffer C, Kampinga $H H$ : BRCA1 and BRCA2 heterozygosity and repair of X-rayinduced DNA damage. Int J Radiat Biol 78: 285-295, 2002

6. Trenz K, Rothfuss A, Schutz P, Speit $G$ : Mutagen sensitivity of peripheral blood from women carrying a BRCA1 or BRCA2 mutation. Mutat Res 500: 89-96, 2002

7. Mamon H, Dahlberg W, Little JB: Hemizygous fibroblast cell strains established from patients with BRCA1 or BRCA2 mutations demonstrate an increased rate of spontaneous mutations and increased radiosensitivity. Int J Radiat Oncol Biol Phys 57(Suppl 2): S346-S347, 2003

8. Rothfuss A, Schutz P, Bochum S, Volm T, Eberhardt E, Kreienberg $R$, Vogel W, Speit $G$ : Induced micronucleus frequencies in peripheral lymphocytes as a screening test for carriers of a BRCA1 mutation in breast cancer families. Cancer Res 60: 390-394, 2000

9. Grant $S G$, Jensen $R H$ : Use of hematopoietic cells and markers for the detection and quantitation of human in vivo somatic mutation. In: Immunobiology of Transfusion Medicine. (Ed: Garratty G), Marcel Dekker, New York, 1993, pp. 299-323

10. Grant SG, Bigbee WL, Langlois RG, Jensen RH: Methods for the detection of mutational and segregational events: relevance to the monitoring of survivors of childhood cancer. In: Late Effects of Treatment for Childhood Cancer. (Eds: Green DM, and D'Angio GJ), Wiley-Liss, New York, 1992, pp. $133-150$

11. Tompa A, Sapi E: Detection of 6-thioguanine resistance in human peripheral blood lymphocytes (PBL) of industrial workers and lung cancer patients. Mutat Res 210: 345-351, 1989

12. Cole J, Skopek TR: Somatic mutant frequency, mutation rates and mutational spectra in the human population in vivo. Mutat Res 304: 33-105, 1994

13. Okada S, Ishii H, Nose H, Okusaka T, Kyogoku A, Yoshimori M, Wakabayashi $K$ : Evidence for increased somatic cell mutations in patients with hepatocellular carcinoma. Carcinogenesis 18: 445-449, 1997

14. Grant $S G$ : Molecular epidemiology of human cancer: biomarkers of genotoxic exposure and susceptibility. J Environ Pathol Toxicol Oncol 20: 245-261, 2001

15. Langlois $R G$, Bigbee $W L$, Jensen $R H$ : The glycophorin A assay for somatic cell mutations in humans. Prog Clin Biol Res 340C: 47-56, 1990

16. Swift M, Morrell D, Massey RB, Chase CL: Incidence of cancer in 161 families affected by ataxia-telangiecasia. N Engl J Med 325: 1831-1836, 1991

17. Kerangueven F, Eisinger F, Noguchi T, Allione F, Wargniez V, Eng C, Padberg G, Theillet C, Jacquemier J, Longy M, Sobol $H$, Birnbaum D: Loss of heterozygosity in human breast carcinomas in the ataxia telangiectasia, Cowden disease and BRCA1 regions. Oncogene 14: 339-347, 1997 
18. Rubinstein WS, Latimer JJ, Sumkin JH, Huerbin M, Grant SG, Vogel VG: Prospective screening study of 0.5 Tesla dedicated magnetic resonance imaging for the detection of breast cancer in young, high risk women. BMC Women's Health 6: 10, 2006

19. Latimer JJ, Rubinstein WS, Johnson JM, Kanbour-Shakir A, Vogel VG, Grant SG: Haploinsufficiency for BRCAl is associated with normal levels of DNA nucleotide excision repair in breast tissue and blood lymphocytes. BMC Med Genet 6: 26, 2005

20. O'Neill JP, McGinniss MJ, Berman JK, Sullivan LM, Nicklas $J A$, Albertini RJ: Refinement of a T-lymphocyte cloning assay to quantify the in vivo thioguanine-resistant mutant frequency in humans. Mutagenesis 2: 87-94, 1987

21. Grant $S G$ : The GPA in vivo somatic mutation assay. Meth Mol Biol 291: 179-195, 2005

22. Jensen $R H$, Bigbee $W L$, Langlois $R G$ : In vivo somatic mutations in the glycophorin A locus of human erythroid cells. Banbury Rep 28: 149-159, 1987

23. Manchester DK, Nicklas JA, O'Neill JP, Lippert MJ, Grant SG, Langlois RG, Moore DH 3rd, Jensen RH, Albertini RJ, Bigbee $W L$ : Sensitivity of somatic mutations in human umbilical cord blood to maternal environments. Environ Mol Mutagen 26: 203-212, 1995

24. Grant SG, Reeger W, Wenger SL: Diagnosis of ataxia telangiectasia with the glycophorin A somatic mutation assay. Genet Testing 1: 261-267, 1998

25. Finette BA, Sullivan LM, O'Neill JP, Nicklas JA, Vacek PM, Albertini RJ: Determination of hprt mutant frequencies in T-lymphocytes from a healthy pediatric population: statistical comparison between newborn, children and adult mutant frequencies, cloning efficiency and age. Mutat Res 308: 223-231, 1994

26. Tates AD, van Dam FJ, van Mossel H, Schoemaker H, Thijssen $J C$, Woldring VM, Zwinderman AH, Natarajan AT: Use of the clonal assay for the measurement of frequencies of HPRT mutants in T-lymphocytes from five control populations. Mutat Res 253: 199-213, 1991

27. Branda RF, Sullivan LM, O'Neill JP, Falta MT, Nicklas JA, Hirsch B, Vacek PM, Albertini RJ: Measurement of HPRT mutant frequencies in T-lymphocytes from healthy human populations. Mutat Res 285: 267-279, 1993

28. Jones IM, Moore DH, Thomas CB, Thompson CL, Strout CL, Burkhart-Schultz $K$ : Factors affecting HPRT mutant frequency in T-lymphocytes of smokers and nonsmokers. Cancer Epidemiol Biomarkers Prev 2: 249-260, 1993

29. Finette BA, Kendall H, Vacek PM: Mutational spectral analysis at the HPRT locus in healthy children. Mutat Res 505: 27-41, 2002

30. Hüttner E, Holzapfel B, Kropf S: Frequency of HPRT mutant lymphocytes in a human control population as determined by the T-cell cloning procedure. Mutat Res 348: 83-91, 1995

31. Becker R, Nikolova T, Wolff I, Lovell D, Hüttner E, Foth H: Frequency of HPRT mutants in humans exposed to vinyl chloride via an environmental accident. Mutat Res 494: 87-96, 2001

32. Sala-Trepat M, Boyse J, Richard P, Papadopoulo D, Moustacchi E: Frequencies of HPRT lymphocytes and glycophorin A variants erythrocytes in Fanconi anemia patients, their parents and control donors. Mutat Res 289: 115-126, 1993

33. Evdokimova VN, McLoughlin RK, Wenger SL, Grant SG: Use of the glycophorin A bone marrow somatic mutation assay for rapid, unambiguous identification of Fanconi anemia homozygotes regardless of GPA genotype. Am J Med Genet 135: 5965,2005
34. Grant SG, Wenger SL, Rubinstein WS, Latimer JJ, Bigbee WL, Auerbach $A D$ : Elevated levels of somatic mutation in homozygotes and heterozygotes for inactivating mutations in the genes of the FA/BRCA DNA repair pathway [abstract]. Am J Hum Genet 75(Suppl): 94, 2004

35. Vijayalaxmi, Wunder E, Schroeder TM: Spontaneous 6-thioguanine-resistant lymphocytes in Fanconi anemia patients and their heterozygous parents. Hum Genet 70: 264-270, 1985

36. Tates AD, Bernini LF, Natarajan AT, Ploem JS, Verwoerd NP, Cole J, Green MHL, Arlett CF, Norris PN: Detection of somatic mutants in man: HPRT mutations in lymphocytes and hemoglobin mutations in erythrocytes. Mutat Res 213: 73-82, 1989

37. Cole J, Green MHL, Stephens G, Waugh AP, Beare D, Steingrimsdottir H, Brideges BA: HPRT somatic mutation data. Prog Clin Biol Res 340C: 25-35, 1990

38. Norris PG, Limb GA, Hamblin AS, Lehmann AR, Arlett CF, Cole J, Waugh AP, Hawk JL: Immune function, mutant frequency, and cancer risk in the DNA repair defective genodermatoses xeroderma pigmentosum, Cockayne's syndrome, and trichothiodystrophy. J Invest Dermatol 94: 94-100, 1990

39. Vermeulen W, Scott RJ, Rodgers S, Muller HJ, Cole J, Arlett CF, Kleijer WJ, Bootsma D, Hoeijmakers JH, Weeda G: Clinical heterogeneity within xeroderma pigmentosum associated with mutations in the DNA repair and transcription gene ERCC3. Am J Hum Genet 54: 191-200, 1994

40. Anstey AV, Arlett CF, Cole J, Norris PG, Hamblin AS, Limb GA, Lehmann AR, Wilkinson JD, Turner M: Long-term survival and preservation of natural killer cell activity in a xeroderma pigmentosum patient with spontaneous regression and multiple deposits of malignant melanoma. Br J Dermatol 125: 272-278, 1991

41. Cole J, Arlett CF, Norris PG, Stephens G, Waugh AP, Beare DM, Green MHL: Elevated hprt mutant frequency in circulating T-lymphocytes of xeroderma pigmentosum patients. Mutat Res 273: 171-178, 1992

42. Lin YW, Kubota M, Hirota H, Furusho K, Tomiwa K, Ochi J, Kasahara Y, Sasaki H, Ohta S: Somatic cell mutation frequency at the HPRT, T-cell antigen receptor and glycophorin A loci in Cockayne syndrome. Mutat Res 337: 49-55, 1995

43. Akiyama M, Kyoizumi S, Hirai Y, Kusunoki Y, Iwamoto KS, Nakamura $N$ : Mutation frequency in human blood cells increases with age. Mutat Res 338: 141-149, 1995

44. Morley AA, Cox S, Holliday R: Human lymphocytes resistant to 6-thioguanine increase with age. Mech Ageing Dev 19: 21-26, 1982

45. Vrieling $H$, Tates $A D$, Natarajan AT, van Zeeland AA: Agerelated accumulation of mutations in human T-lymphocytes. Ann N Y Acad Sci 663: 36-42, 1992

46. Branda RF, O'Neill JP, Jacobson-Kram D, Albertini RJ: Factors influencing mutation at the hprt locus in T-lymphocytes: studies in normal women and women with benign and malignant breast masses. Environ Mol Mutagen 19: 274-281, 1992

47. Latimer JJ, Kisin E, Zayas-Rivera B, Kanbour-Shakir A, Kelley $J$, Johnson R, Grant $S G$ : Increased somatic mutation and reduced DNA repair in breast cancer patients and their tumors [abstract]. Proc Am Assoc Cancer Res 40: 440, 1999

48. Nicklas JA, Lippert MJ, Hunter TC, O'Neill JP, Albertini RJ: Analysis of human HPRT deletion mutations with X-linked probes and pulsed field gel electrophoresis. Environ Mol Mutagen 18: 270-273, 1991

49. Papadopoulo D, Guillouf C, Mohrenweiser H, Moustacchi E: Hypomutability in Fanconi anemia cells is associated with increased deletion frequency at the HPRT locus. Proc Natl Acad Sci USA 87: 8383-8387, 1990 
50. Laquerbe A, Sala-Trepat M, Vives C, Escarceller M, Papadopoulo D: Molecular spectra of HPRT deletion mutations in circulating T-lymphocytes in Fanconi anemia patients. Mutat Res 431: 341-350, 1999

51. Elmore E, Swift M: Growth of cultured cells from patients with Fanconi anemia. J Cell Physiol 87: 229-233, 1975

52. Weksberg $R$, Buchwald M, Sargent P, Thompson MW, Siminovitch $L$ : Specific cellular defects in patients with Fanconi anemia. J Cell Physiol 101: 311-323, 1979

53. Thompson LH: Nucleotide excision repair: its relation to human disease. In: DNA Damage and Repair, Volume 2: DNA Repair in Higher Eukaryotes. (Eds: Nickoloff JA and Hoekstra MF), Humana, Totowa, NJ, 1998, pp. 335-393

54. Hartman A-R, Ford JM: BRCA1 induces DNA damage recognition factors and enhances nucleotide excision repair. Nat Genet 32: 180-184, 2002
55. Takimoto R, MacLachlan TK, Dicker DT, Niitsu Y, Mori T, elDeiry WS: BRCA1 transcriptionally regulates damaged DNA binding protein (DDB2) in the DNA repair response following UV-irradiation. Cancer Biol Ther 1: 177-186, 2002 (comment 1: 187-188, 2002)

56. Kovacs E, Stucki D, Weber W, Muller H: Impaired DNA-repair synthesis in lymphocytes of breast cancer patients. Eur J Cancer Clin Oncol 22: 863-869, 1986

57. Xiong P, Bondy ML, Li D, Shen H, Wang LE, Singletary SE, Spitz MR, Wei $Q$ : Sensitivity to benzo[a]pyrene diol-epoxide associated with risk of breast cancer in young women and modulation by glutathione S-transferase polymorphisms: a case-control study. Cancer Res 61: 8465-8469, 2001

58. Kennedy DO, Agrawal M, Shen J, Terry MB, Zhang FF, Senie $R T$, Motykiewicz G, Santella RM: DNA repair capacity of lymphoblastoid cell lines from sisters discordant for breast cancer. J Natl Cancer Inst 97: 127-132, 2005 